\title{
Associational Involvement in Dutch Municipalities and Neighbourhoods: Does Ethnic Diversity Influence Bonding and Bridging Involvement?
}

\author{
Michael Savelkoul, Maurice Gesthuizen, and Peer Scheepers \\ Department of Sociology, Radboud University Nijmegen, P.O. Box 9104, 6500 HE Nijmegen, Netherlands \\ Correspondence should be addressed to Michael Savelkoul; m.savelkoul@maw.ru.nl
}

Received 21 January 2015; Revised 12 May 2015; Accepted 24 May 2015

Academic Editor: David Wong

Copyright (C) 2015 Michael Savelkoul et al. This is an open access article distributed under the Creative Commons Attribution License, which permits unrestricted use, distribution, and reproduction in any medium, provided the original work is properly cited.

\begin{abstract}
We test whether ethnic diversity in Dutch neighbourhoods and municipalities drives down associational involvement and build on earlier research in two important ways. First, we explicitly take into account the ethnic composition of local voluntary associations, distinguishing involvement in bonding (only in-group members) and bridging (with out-group members) associations. Second, we aim to explain relationships between ethnic diversity and associational involvement, testing two competing sets of predictions derived from conflict and contact theories. Using data from the Netherlands Longitudinal Lifecourse Study (2013), ethnic diversity turns out to hardly affect associational involvement negatively. Only for leisure associations, living in ethnically more diverse municipalities substantially decreases the likelihood to be involved in bonding associations, whereas higher levels of neighbourhood ethnic diversity increase the likelihood to be involved in bridging associations. Moreover, ethnic diversity indirectly affects associational involvement via interethnic contact. Higher levels of ethnic diversity increase interethnic contact which, in turn, is negatively related to involvement in bonding associations. Whereas higher levels of ethnic diversity in neighbourhoods increase perceptions of ethnic threat, these perceptions decrease with higher levels of ethnic diversity in the municipality. Perceptions of ethnic threat do not, however, affect associational involvement. Our results shed more light on the direct and indirect relationships between ethnic diversity and bonding and bridging associational involvement.
\end{abstract}

\section{Introduction}

In recent decades, many Western countries faced rising levels of ethnic diversity, which is expected to continue in the future $[1,2]$. These changes have spurred strong debates among scholars and politicians about the societal consequences of ethnic diversity. Particularly Putnam's [3] study on the consequences of ethnic diversity in the US attracted much attention, as he claimed that, in the short run at least, ethnic diversity would have an all-embracing negative impact on "[...] attitudes and behaviors, bridging and bonding social capital, public and private connections" ([3], 151). According to Putnam, people living in ethnically more diverse neighbourhoods would tend to "hunker down" ([3], 149), meaning that they are less trusting, have less informal social ties, and are less likely to be involved in voluntary associations.

In recent years, a rapidly growing body of research addressed the impact of ethnic diversity in Western societies on a broad range of indicators of social cohesion (see recent review articles by $[4,5])$. In this study, we focus on the consequences of living in ethnically more diverse environments for natives' level of associational involvement (i.e., formal social capital; cf. [6]). In their review of studies, van der Meer and Tolsma [5] conclude that evidence for a pernicious impact of ethnic diversity is particularly weak for associational involvement. As we will argue in more detail below, the absence of a general negative effect of ethnic diversity might be caused by the design of earlier studies in the field. In this study, we aim to fill this lacuna and to 
contribute to the existing body of research in two important ways.

First, we will consider the ethnic composition of voluntary associations. This enables us to differentiate between involvement in associations with only ethnic in-group members (i.e., bonding associations) and involvement in associations in which also ethnic minority members are involved (i.e., bridging associations). In the latter type of organizations, people are able to socialize with other members belonging to different ethnic groups, which is not the case in bonding associations. According to Putnam [3], ethnic diversity would have a detrimental impact on both bridging and bonding social capital. Remarkably, the vast majority of studies addressing the relationship between ethnic diversity and behavioural indicators of social capital have overlooked this crucial distinction (see also [7] $)^{1}$. Only very recently, two studies focused on the influence of ethnic diversity on bonding and bridging informal social capital in people's direct social surroundings. Huijts and colleagues $[8,9]$ showed that people living in areas with a larger proportion of ethnic minority members (and, consequently, a smaller proportion of ethnic majority members) have less informal contacts with ethnic majority members, while having more contacts with ethnic minorities. In the present study, we focus on the relationship between ethnic diversity and bridging and bonding formal social capital, considering the ethnic composition of voluntary associations. This enables us to put Putnam's claim of a general negative effect of ethnic diversity on both bonding and bridging associational involvement to a more rigorous test than has been done so far. Note that earlier studies which neglected the distinction between bonding and bridging social capital might also face methodological difficulties. Should ethnic diversity have contradictory influences on involvement in bonding and bridging associations, such effects might cancel each other out. This might be an explanation why earlier studies, neglecting this distinction, hardly found evidence for a detrimental influence of ethnic diversity [5].

Apart from using more fine-grained measures of associational involvement, we will build on earlier studies by focusing on underlying explanations for the relationship between ethnic diversity and formal social capital. Until now, it remains largely unclear how ethnic diversity affects associational involvement. Based on conflict theory (e.g., [10-12]) and contact theory (e.g., [13-15]) we derive two contrary sets of expectations on underlying mechanisms, just like Savelkoul et al. [16], who failed, however, to consider the ethnic composition of these associations. As such contradictory indirect effects might cancel each other out, this might be an alternative explanation why studies only addressing direct relationships between ethnic diversity and formal social capital hardly found evidence for a detrimental impact of ethnic diversity [5].

In this study, we address associational involvement in local communities in the Netherlands. The Netherlands is one of the countries with the highest levels of associational involvement in Europe [17-19]. We will only focus on voluntary associations that are locally oriented, serving needs of locals, that is, associations at the level of neighbourhoods or municipalities, in people's direct social surroundings. We will use data from the Netherlands Longitudinal Life Course Study 2013 [20, 21], complemented with information on the level of ethnic diversity in people's living environment. In line with earlier studies on the influence of ethnic diversity on social capital in the Netherlands $[8,9,22]$, we will consider the ethnic composition of the neighbourhood as well as the municipality level. Although both contextual levels reflect people's direct living environment, the municipality level might be relevant on different domains of life (e.g., work and family) as compared to the neighbourhood where people live. We suppose, however, that both levels might be important when it comes to leisure and associational involvement. We address the following research questions.

(1) To what extent does ethnic diversity within Dutch neighbourhoods and municipalities affect bonding and bridging formal social capital?

(2) How can these relationships be explained by mechanisms derived from conflict and contact theories?

\section{Theory and Hypotheses}

We set out to explore three general theories (i.e., constrict, conflict, and contact theories), which put forward contradictory (in-)direct effects of ethnic diversity on bonding and bridging formal social capital. We focus on the influence of ethnic diversity at the municipality and neighbourhood level in the Netherlands (cf. $[8,22]$ ), which reflects people's direct living environment. Earlier research pointed at the fact that, as compared to more distant levels of analysis, like the country or state level, such relatively small units of analyses better cover people's actual interaction settings, influencing people's attitudes and behaviour [23]. As we are interested in involvement in locally oriented voluntary associations (e.g., sport, cultural, and neighbourhood associations), the municipality and neighbourhood level can be regarded as the relevant contextual environment. Should ethnic diversity affect associational involvement in such locally oriented organizations, we expect that this influence is most likely to be found at these local levels.

Although one would intuitively expect stronger effects at the neighbourhood level as compared to the municipality level, earlier research on general associational involvement in the Netherlands found an effect of ethnic diversity only at the municipality level [22]. In line with previous studies in the Netherlands $[8,9,22]$, we decided to formulate similar hypotheses for the influence of ethnic diversity at the neighbourhood and municipality level. Taking into account both contextual levels simultaneously, we are able to test more accurately whether the influence of ethnic diversity is similar or might differ at both levels.

2.1. Constrict Theory. Although the underlying theoretical rationale of Putnam's constrict theory remains implicit, one can summarize its core statement as follows: higher levels of ethnic diversity cause "[...] anomie or social isolation," inducing people to withdraw from social life ([3], 149). According to Putnam [3], this effect would be rather general, 
reducing formal and informal bonding and bridging social capital. In recent years, constrict theory has been repeatedly criticized as the underlying reasons for the supposed negative influence of ethnic diversity remain theoretically underexplored $[5,7]$.

Gesthuizen et al. [18] pointed at the importance of the principle of homophily in this respect. Based on the general assumption that people prefer social ties with people who are alike, for instance, regarding their ethnicity (see [24]), living in ethnically diverse neighbourhoods or municipalities can cause people to feel less comfortable, as there are less people of one's own kind around with whom people can socially identify and with whom people feel familiar. According to Gesthuizen and colleagues [18], such feelings of discomfort might cause people to withdraw from social life entirely or at least partly, including bonding and bridging voluntary associations. Therefore, based on Putnam's constrict theory, we expect that

(1) higher levels of ethnic diversity within Dutch neighbourhoods and municipalities will be negatively related to people's likelihood to be involved in any type of voluntary associations, either bonding or bridging.

As our aim is particularly to understand how living in ethnically diverse environments affects people's likelihood to be involved in bonding or bridging associations, we will apply two intergroup theories (i.e., conflict and contact theories), to derive more explicit hypotheses on underlying explanations.

2.2. Conflict Theory. According to conflict theory [10-12, $25,26]$, ethnic diversity is considered to foster ethnic competition between natives and ethnic minorities regarding economic and cultural issues. With higher levels of ethnic diversity, natives have to compete more strongly with ethnic minorities for scarce jobs or affordable housing. Likewise, conflicting values or competition about privileges becomes more prevalent if the proportion of ethnic minorities is larger. Consequently, higher levels of ethnic diversity are expected to increase perceptions of ethnic threat, which in turn increase both in-group solidarity and out-group derogation $[12,26]$. It is particularly the latter effect which has been subject to numerous studies in the past and has been corroborated time and again. People who perceive more ethnic threat, hold more negative attitudes towards ethnic out-group members (e.g., $[12,27,28])$.

Based on conflict theory, we expect that ethnic diversity might also affect associational involvement by inducing both in-group solidarity and out-group derogation. On the one hand, people perceiving more ethnic threat might be less likely to be involved in bridging voluntary associations. These people hold more negative attitudes towards ethnic minorities and might consequently avoid involvement in voluntary associations with (many) out-group members. On the other hand, due to increased in-group solidarity, people who feel threatened by the presence of ethnic minorities might become stimulated to focus completely on bonding voluntary associations, where they will be surrounded exclusively with ethnic in-group members. Hence, we expect that
(2) higher levels of ethnic diversity within Dutch neighbourhoods and municipalities will increase perceptions of ethnic threat (2a). Moreover, we propose that people who perceive (more) ethnic threat will be less likely to be involved in bridging voluntary associations (2b), while being more likely to be involved in bonding voluntary associations (2c).

Although conflict theory might be useful to understand how living in ethnically diverse environments might influence associational involvement, it leads to different expectations as compared to constrict theory. Whereas constrict theory predicts that ethnic diversity generally erodes involvement in voluntary associations, irrespective of the ethnic composition, based on conflict theory, one would expect ethnic diversity to reduce only bridging formal social capital.

In line with van der Meer and Tolsma [5], we propose that the "threat mechanism" might also be the underlying explanation for a general negative influence of ethnic diversity, as predicted by constrict theory [3]. In that case, we derive an opposite expectation for the relationship between ethnic threat perceptions and bonding associational involvement: the more people perceive ethnic threat, the less likely they will be involved in any voluntary association, either bridging or bonding. Earlier cross-national European research provided some initial evidence for this line of thought, showing that people, who perceive more ethnic threat, are less likely to be involved in different types of voluntary associations [16]. Note, however, that the ethnic composition of the voluntary associations was not considered. In sum, and contradictory to hypothesis (2c), we expect that

(2d) people who perceive (more) ethnic threat will be less likely to be involved in bonding voluntary associations.

The "threat mechanism" might, however, be more complex and might also affect the choice for bonding or bridging associations for those people who decide to become involved. While perceiving ethnic threat might induce a general tendency to withdraw from social life, meaning that people with higher levels of perceived ethnic threat are less likely to be involved in voluntary associations, irrespective of their ethnic composition (cf. constrict theory), based on conflict theory, one would expect that perceiving ethnic threat might simultaneously foster feelings of in-group solidarity [26]. Therefore, we propose that, for those people who decide to become involved in voluntary associations, perceptions of ethnic threat make them less likely to be involved in bridging as compared to bonding voluntary associations. Summarizing, we expect that

(2e) people who are involved in voluntary associations and perceive (more) ethnic threat will be less likely to be involved in bridging as compared to bonding voluntary associations.

2.3. Contact Theory. According to contact theory [13-15], positive interethnic contact effectively reduces negative attitudes towards ethnic minorities. Previous research repeatedly showed that larger proportions of ethnic minorities in people's living environment increase the likelihood of interethnic 


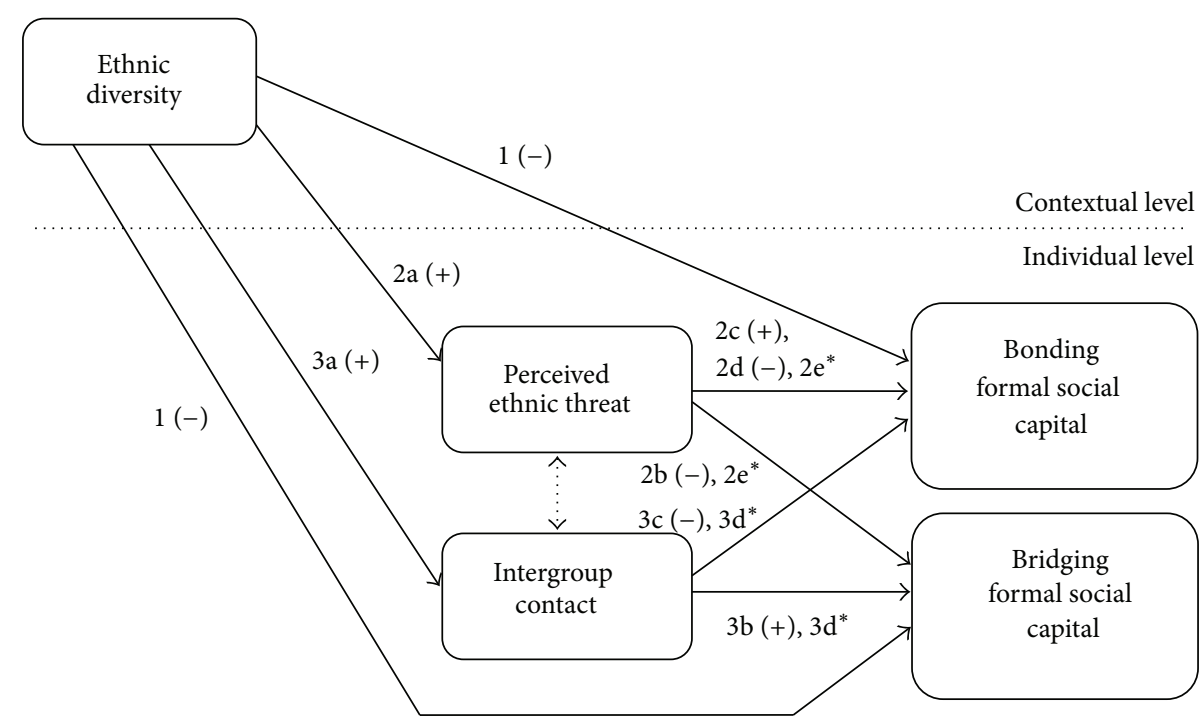

Figure 1: Theoretical framework relationship between ethnic diversity and bonding and bridging formal social capital. Note that all relationships are controlled for relevant control variables at the individual and contextual level. * Additional hypotheses on the likelihood to be involved in bridging as compared to bonding voluntary association.

contact, which in turn reduces out-group derogation (e.g., [28-30]).

We propose that interethnic contact might also be important for explaining people's likelihood to be involved in bonding and bridging voluntary associations. Wilson [31] argued that people's social network is important for coming to know about the existence of a voluntary association or for becoming recruited to participate or volunteer. If people's social network is ethnically more diverse, due to higher levels of interethnic contact, they might predominantly come to know of the existence of bridging voluntary associations or even become recruited into such associations ${ }^{2}$. However, interethnic contact might stimulate bridging formal social capital in a different way as well. Earlier studies have consistently shown that interethnic contact increases empathy and reduces negative attitudes towards ethnic minorities as well as anxiety about interacting with them [15, 32, 33]. Consequently, interethnic contact might make people feel less anxious about encountering ethnic out-group members during activities of these voluntary associations, taking away a psychological threshold to become involved in ethnically mixed associations. Based on this argumentation, we expect that interethnic contact will be positively related to people's likelihood of being involved in bridging associations.

Simultaneously, having intergroup contact can also reshape people's view of their ethnic in-group. In this respect, Pettigrew [14] points at a "deprovincialization" effect, meaning that intergroup contact stimulates people to reassess the customs and values of their own ethnic group as these turn out not to be the only way to deal with the social world. Based on the homophily principle [24], we expect people to generally prefer involvement in bonding associations, as in such associations they are surrounded by similar others. Having intergroup contact might, however, reshape these preferences, as people might become less strongly focused on bonding voluntary associations. Additionally, having more interethnic contact might reduce contact with ethnic ingroup members. Although inter- and intragroup contacts are not completely mutually exclusive, due to time restrictions, one might expect at least some negative correlation. People who have less contact with in-group members might, consequently, be less likely to become recruited into bonding associations. Summarizing, we expect that

(3) higher levels of ethnic diversity within Dutch neighbourhoods and municipalities will increase the likelihood of interethnic contact (3a). In addition, we propose that people who have interethnic contact will be more likely to be involved in bridging voluntary associations (3b), while being less likely to be involved in bonding voluntary associations ( $3 c$ ).

Additionally, we expect that interethnic contact might also influence the choice for bonding or bridging associations for those people who are involved. Based on the considerations related to recruitment, psychological thresholds to become involved in bridging associations, and the supposed "deprovincialization" effect of interethnic contact, we expect that

(3d) people who are involved in voluntary associations while having interethnic contact, are more likely to be involved in bridging as compared to bonding voluntary associations.

For a summary of our theoretical framework, see Figure 1. The numbers refer to our hypotheses. 


\section{Data and Measurements}

To test our hypotheses, we use data from the second wave of the Netherlands Longitudinal Lifecourse Study [20, 21]. The NELLS is a large-scale survey of the Dutch population aged 15-45 (in wave 1). For the first wave, a two-stage stratified sampling design was applied. First, municipalities were selected quasi-randomly by urbanization and region. Second, a random selection was drawn from the population registry based on age and country of birth of the respondent and the respondent's parents. For the second wave (which will be used in this study), respondents with complete information in wave 1 and who stated that they could be contacted again were asked to participate ${ }^{3}$. The fieldwork was conducted between February and December 2013 under the direction of Radboud University Nijmegen, Tilburg University, and University of Amsterdam. The fieldwork has been conducted in a mixed mode, using both web surveys and face-to-face interviews. For each residential address, the geolocation (i.e., latitude and longitude) was used for the assignment of neighbourhoods and municipalities of the residential address. Next, these geolocations were positioned on the 2012 ESRI shapefiles of Statistics Netherlands (for more information, see [21]).

We use the second wave of the NELLS-survey, as only this wave contains the most precise and valid measures of the phenomena which are central in this study. We only included native Dutch respondents, of whom both parents were born in the Netherlands. Earlier studies have emphasized the differential effect of living in an ethnically diverse environment on majority and minority populations, usually stressing a larger, and occasionally only an, effect for majority populations $[23,34]$. Moreover, including ethnic minority respondents is impossible as we cannot construct our measures of bonding and bridging formal social capital in a similar way as has been done for native respondents. Unless stated differently, we excluded respondents (6.58\%) with missing values on one or more variables listwise, resulting in a working sample of 1,604 respondents living in 630 neighbourhoods, located in 58 municipalities in the Netherlands.

3.1. Dependent Variables: Bonding and Bridging Formal Social Capital. Formal social capital refers to involvement in formally constituted associations as well as activities $([6], 424)$. The NELLS-survey includes a fine-grained measurement of involvement in different types of voluntary associations, including the ethnic composition of these associations, which is rather unique. Based on the ethnic composition, we are able to distinguish between bonding formal social capital (only ethnic in-group members) and bridging formal social capital (also including ethnic out-group members).

As mentioned earlier, we distinguish between involvement in leisure and interest organizations, which both can be regarded as locally oriented associations with relatively high levels of face-to-face contact. In this study, leisure associations refer to "sport associations" and "associations for hobby, music, or culture." Interest associations refer to "neighbourhood or community associations or tenants associations." Only respondents, who are a member of an association, were asked about the ethnic composition of this association $^{4}$.

For each type of association, respondents were asked whether they are involved in an association with (i) no, (ii) some, (iii) many, or (iv) almost only ethnic out-group members. For leisure and interest associations separately, we distinguish respondents who are not involved (reference category), respondents who are involved in bonding associations (with only in-group members), and respondents who are involved in bridging associations (also including out-group members $)^{5}$.

\subsection{Independent Variables at the Contextual Level: Ethnic} Diversity. To measure ethnic diversity at the neighbourhood and municipality level, we constructed two commonly used measures: migrant stock and ethnic fractionalization (e.g., $[3,18,35])$. Both measures are based on figures from 2012 derived from Statistics Netherlands [36]. First, migrant stock refers to the percentage of ethnic minorities from nonWestern descent (cf. [8,9]). The largest groups of nonWestern minorities in the Netherlands are Turks, Moroccans, Surinamese, and Antilleans. Second, we calculated the level of ethnic fractionalization, distinguishing native Dutch, Western minorities, and non-Western minorities (cf. [22]). Ethnic fractionalization is based on the complement of the Herfindahl index (HI) (see e.g., [37], 159) and reflects the probability that two randomly chosen individuals in a municipality or neighbourhood belong to a different (ethnic) group. Note that this measure has been repeatedly criticized for its colour blindness [22, 38]. As both indicators are strongly correlated (at the municipality level: $r=.90$; at the neighbourhood level: $r=.72$ ) we will test our hypotheses using the migrant stock measure and will use the ethnic fractionalization measure for additional robustness analyses.

\subsection{Mediating Variables: Interethnic Contact with Friends and} Perceived Ethnic Threat. To assess whether respondents have interethnic contact with friends, we used four dichotomous items asking respondents whether or not they have ethnic minority friends from (i) Turkish, (ii) Moroccan, (iii) Surinamese/Antillean, or (iv) other non-Western descents. In line with our migrant stock measure, we focus on non-Western minorities solely. Interethnic contact with friends can be regarded as voluntary in nature and rather intimate and is, therefore, supposed to meet the key conditions of the contact hypothesis $[13,14]$. We constructed a dichotomous measure of intergroup friendship, referring to interethnic friendship ties with members of any ethnic minority group ${ }^{6}$.

To measure the respondents' level of perceived ethnic threat, we use five items referring to economic and noneconomic issues: "one day it might come so far that Dutch people will be fired to hire ethnic minorities," "the immigration of ethnic minorities threatens Dutch culture," "education of ethnic minorities happens at the expense of Dutch children's education," "I sometimes worry that the quality of my living environment diminishes due to the immigration of ethnic minorities," and "I am afraid that my financial prospects deteriorate due to the presence of ethnic minorities" 
TABLE 1: Variance components municipality and neighbourhood level.

\begin{tabular}{|c|c|c|c|c|c|c|}
\hline & \multicolumn{2}{|c|}{ Bonding versus not involved } & \multicolumn{2}{|c|}{ Bridging versus not involved } & \multicolumn{2}{|c|}{ Bridging versus bonding } \\
\hline & M0 & M1 & M0 & M1 & M0 & M1 \\
\hline \multicolumn{7}{|l|}{ Leisure } \\
\hline Municipality & .193 & .166 & .024 & .000 & .128 & .055 \\
\hline Neighbourhood & .054 & .067 & .000 & .000 & .000 & .000 \\
\hline \multicolumn{7}{|l|}{ Interest } \\
\hline Municipality & .758 & .810 & .301 & .315 & .091 & .046 \\
\hline Neighbourhood & .357 & .342 & .326 & .360 & .135 & .190 \\
\hline
\end{tabular}

Sources: Netherlands Longitudinal Lifecourse Survey [20].

M0 = null model (random intercept only); M1 = random intercept + individual level variables. BOND = involved in bonding voluntary association; BRID = involved in bridging voluntary association; $\mathrm{NI}=$ not involved in voluntary association.

The answer categories range from "disagree strongly" to "agree strongly" on a five-point scale. In addition, the answer category "never thought about" was given. The perceived ethnic threat scale is calculated by the mean score on the five items, for respondents with at least three valid answers (Cronbach's alpha: .88). Higher scores reflect higher levels of perceived ethnic threat.

\subsection{Control Variables at the Contextual and Individual Level.} Earlier research pointed at the importance of adequately controlling for the socioeconomic status of the context when addressing the influence of ethnic diversity on social capital (e.g., $[22,39])$. In line with previous studies (e.g., $[8,9,16])$, we control for the unemployment rate at the contextual level. We use the number of unemployment benefit recipients per 1,000 inhabitants aged 15-64 in 2012 at the municipality and neighbourhood level [36].

At the individual level, we control for several determinants which have been found to influence associational involvement, interethnic contact, or perceived ethnic threat (e.g., $[28,31,40-42])$. The level of educational attainment was measured by the highest level of education completed by the respondent. For respondents who are still in education, we used the current level of education. We decided to condense the original twelve categories (ranging from no education to a Ph.D. degree) and distinguished four levels of education: (i) at most lower secondary education, (ii) higher secondary/intermediate vocational education, (iii) vocational college, and (iv) university (reference category) ${ }^{8}$. Additionally, we considered whether respondents were still studying and/or working at least 12 hours a week, distinguishing three categories: "only working" (reference category), "studying," and "neither working nor studying." For measuring the respondent's income, we used an item referring to the monthly income of the respondent and his/her partner. Four income categories were distinguished: "less than 1,500 euro," "1,500-2,499 euro," "2,500-3,499 euro," and "3,500 euro or more" (reference category). We included an additional category for respondents lacking valid information on their income. Religiosity was measured asking respondents how often they attend religious services. We distinguished three categories: "never" (reference category), "less than once a month," and "once a month or more." Additionally, we control for having a partner (reference category: "no partner") and having children (reference category: "no children"). Finally, we use straightforward measures of gender (with males as reference category) and age (based on the date of birth and the date of interview and subtracting the minimum age for a meaningful interpretation of the intercept). Descriptive statistics are summarized in Table 4.

\section{Analyses}

To test our hypotheses and taking into account the hierarchical structure of our data, with individuals nested within neighbourhoods, which are nested in municipalities, we will conduct multilevel (multinomial) regression analyses. For both leisure and interest associations, we will consider three contrasts: the odds of involvement in bonding and, respectively, bridging voluntary associations as compared to not being involved, and the odds of involvement in bridging as compared to bonding voluntary associations.

First, we estimated null models, only including random intercepts, to estimate the variance at the neighbourhood and municipality level (see Table 1, Model 0). In Model 1 in Table 1, we additionally included our individual-level predictors to test whether any variance at the contextual level is explained by composition effects of individual-level determinants. For leisure associations most variance is found at the municipality level ${ }^{9}$. For interest associations also at the neighbourhood level a substantial variance is found. In some cases the variance is rather small or even estimated as zero (i.e., redundant). In line with Snijders and Bosker ([43], 106), who argued that a positive and significant random intercept variance is not necessary, if one has a theoretical justification for testing the effect of contextual-level variables, we will conduct three-level multinomial regression analyses to test our hypotheses.

We will test our hypotheses in three steps and will present our findings based on the migrant stock measure. First, we estimate the direct effects of migrant stock on bonding and bridging formal social capital, considering the three contrasts mentioned before (Table 2; Models 1 and 2): the odds of involvement in bonding associations versus not being involved (Model a), the odds of involvement in bridging associations 
TABLE 2: Results of hierarchical multinomial regression analyses, direct contextual-level effects $\left(N_{\text {individual }}=1,604 ; N_{\text {neighbourhood }}=630\right.$; $N_{\text {municipality }}=58$ ).

\begin{tabular}{|c|c|c|c|c|c|c|}
\hline & \multicolumn{3}{|c|}{ Leisure } & \multicolumn{3}{|c|}{ Interest } \\
\hline & M1a & M1b & M1c & M2a & M2b & $\mathrm{M} 2 \mathrm{c}$ \\
\hline & $\begin{array}{l}\text { Bonding versus } \\
\text { not involved }\end{array}$ & $\begin{array}{l}\text { Bridging versus } \\
\text { not involved }\end{array}$ & $\begin{array}{l}\text { Bridging versus } \\
\text { bonding }\end{array}$ & $\begin{array}{l}\text { Bonding versus } \\
\text { not involved }\end{array}$ & $\begin{array}{l}\text { Bridging versus } \\
\text { not involved }\end{array}$ & $\begin{array}{l}\text { Bridging versus } \\
\text { bonding }\end{array}$ \\
\hline Intercept & $-.500(.521)$ & $-.021(.488)$ & $.509(.598)$ & $\begin{array}{c}-6.192 \\
(1.276)^{* * *}\end{array}$ & $\begin{array}{c}-4.599 \\
(1.080)^{* * *}\end{array}$ & $.735(1.390)$ \\
\hline Migrant stock municipality & $-.035(.016)^{* *}$ & $-.015(.014)$ & $.020(.018)$ & $-.023(.040)$ & $-.049(.032)$ & $-.015(.043)$ \\
\hline Unemployment municipality & $.027(.017)$ & $-.000(.016)$ & $-.029(.019)$ & $.097(.039)^{* *}$ & $.023(.033)$ & $-.043(.038)$ \\
\hline Migrant stock neighbourhood & $-.016(.013)$ & $.026(.010)^{* * *}$ & $.047(.015)^{* * *}$ & $-.145(.042)^{* * *}$ & $.026(.020)$ & $.166(.045)^{* * *}$ \\
\hline Unemployment neighbourhood & $-.015(.009)$ & $-.024(.010)^{* *}$ & $-.009(.012)$ & $.005(.014)$ & $-.009(.016)$ & $-.018(.020)$ \\
\hline
\end{tabular}

Sources: Netherlands Longitudinal Lifecourse Survey [20], Statistics Netherlands [36].

${ }^{* * *}$ Significant at $p<.01 ;{ }^{* *}$ significant at $p<.05 ;{ }^{*}$ significant at $p<.10$ (two-sided test of significance). All models include individual-level control variables (results available upon request).

versus not being involved (Model b), and the odds of involvement in bridging versus bonding associations (Model c). Next, we will address the influence of the percentage non-Western minorities on both mediating variables, that is, perceived ethnic threat and interethnic contact (Table 3, Models 3 and 4), conducting hierarchically linear regression analysis and, respectively, hierarchical logistic regression analysis. Subsequently, we will test the indirect effect of migrant stock on associational involvement, taking into account the influence of both mediating variables (Table 3, Models 5 and 6).

Finally, we will conduct several robustness analyses. At the municipality and neighbourhood level we will consider the influence of ethnic fractionalization (instead of our migrant stock measure). Moreover, as several studies (e.g., $[5,44])$ pointed at the importance of ethnic segregation, we will additionally control for segregation at both levels ${ }^{10}$. Furthermore, we use our alternative measure of intergroup contact (i.e., interethnic contact at work/school). Generally, our robustness analyses yield substantially similar conclusions as presented in Tables 2 and 3 with some minor exceptions (results available upon request) ${ }^{11}$.

\section{Results}

The first aim of this study is to test whether living in ethnically more diverse neighbourhoods and municipalities is negatively related to involvement in bonding and bridging voluntary associations (hypothesis 1), as claimed by Putnam [3]. As shown in Table 2 (Model 1a), living in municipalities with a larger percentage of non-Western minorities is negatively related to the odds of involvement in bonding leisure associations. However, higher levels of migrant stock in neighbourhoods are positively related to the odds of involvement in bridging leisure associations as compared to not being involved (Table 2, Model $1 \mathrm{~b}$ ), as well as the odds of involvement in bridging as compared to bonding leisure associations (Table 2, Model 1c) ${ }^{12}$.

For interest associations our results reveal a rather similar picture, though only at the neighbourhood rather than at the municipality level. Again, living in neighbourhoods with higher percentages of non-Western minorities is negatively related to the odds of involvement in bonding interest associations (Table 2, Model 2a). Moreover, higher levels of migrant stock are positively related to the odds of involvement in bridging as compared to bonding interest associations (Table 2, Model 2c). We did not, however, find an effect of ethnic diversity on the odds of involvement in bridging interest associations as compared to not being involved (Table 2, Model 2b) ${ }^{13}$.

So far, we considered the influence of migrant stock on the odds of involvement in bonding or bridging associations. Figure 2 shows the predicted probabilities to be (i) not involved, (ii) involved in bonding associations, and (iii) involved in bridging associations for leisure and interest associations separately ${ }^{14}$. Only for leisure associations, the influence of ethnic diversity is substantial, whereas for interest associations this impact is relatively small, though significant. The probability to be involved in bridging leisure associations, for instance, is thirty-percentage points higher for people living in the most ethnically heterogeneous neighbourhoods as compared to those living in the least heterogeneous neighbourhoods. Note, however, that, for leisure associations, the influence of ethnic diversity differs between the municipality and neighbourhood level. Whereas at the municipality level the probability of noninvolvement increases with higher levels of ethnic diversity, at the neighbourhood level the probability of being not involved decreases when levels of migrant stock are higher. At the municipality level this is due to decreasing levels of involvement in bonding associations, whereas at the neighbourhood level the probability of involvement in bridging associations increases, resulting in lower probabilities of noninvolvement. Yet, also at the neighbourhood level, the probability to be involved in bonding 

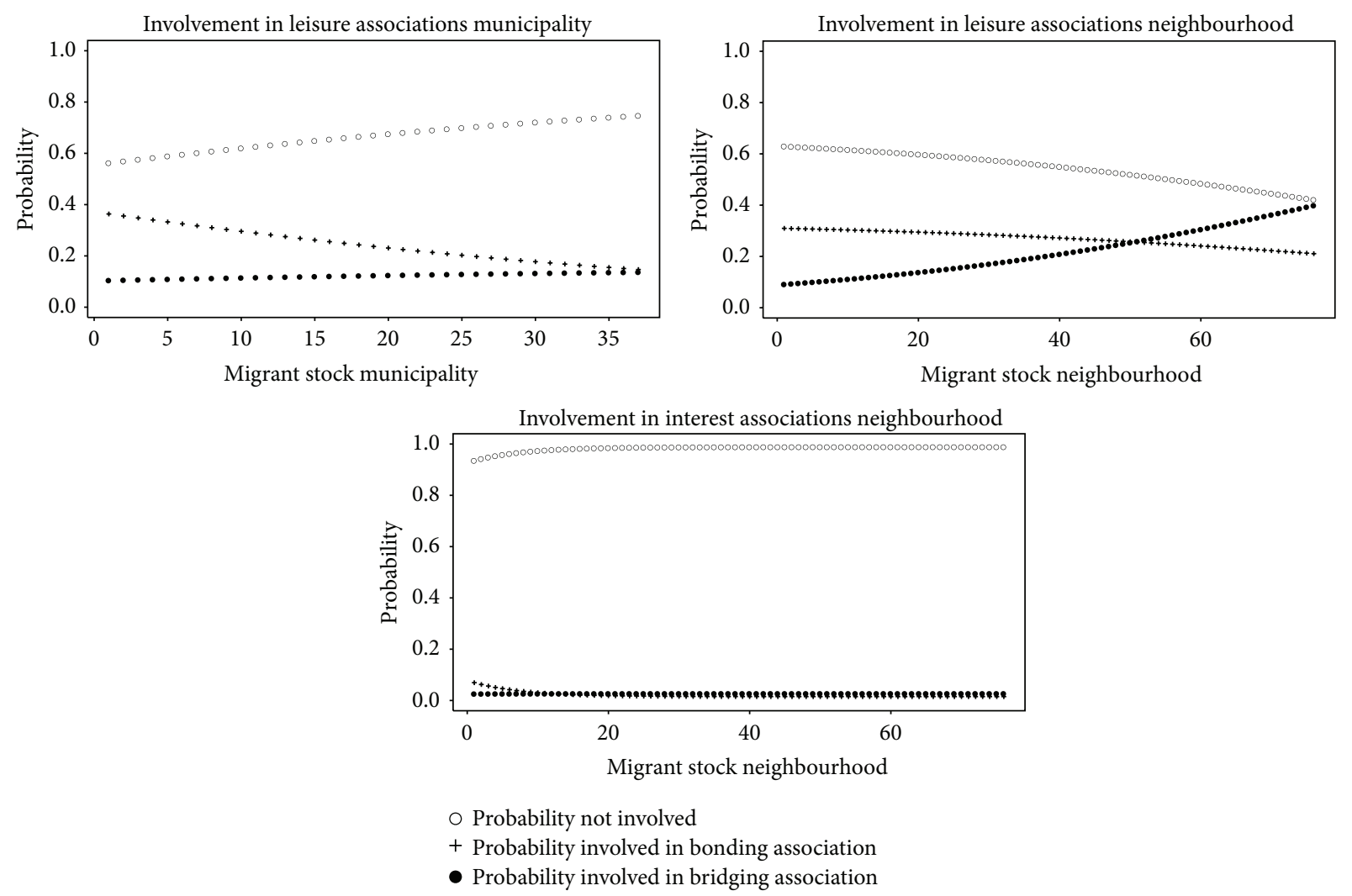

FIGURE 2: Estimated probabilities involvement in leisure and interest associations.

associations slightly decreases when migrant stock levels are higher.

Our second research question focuses on underlying explanations for a relationship between ethnic diversity and associational involvement derived from conflict [11, 12, 25] and contact theories [13-15]. If we include both mediating mechanisms (i.e., perceived ethnic threat and interethnic contact) in our models (Table 3 ), the influence of migrant stock on associational involvement remains substantially similar as compared to Table 2. Note that both mediating mechanisms are negatively related (Table 3 , Models 3 and 4 ) ${ }^{15}$.

Living in municipalities or neighbourhoods with more minorities from non-Western descent increases the likelihood to have interethnic contact with friends (Table 3, Model 4). Having interethnic contact, in turn, is negatively related to the odds of involvement in bonding associations, but only for leisure associations (Table 3, Model 5a). Additionally, having interethnic contact is positively related to the likelihood to be involved in bridging as compared to bonding associations for those respondents who are involved in leisure associations (Table 3, Models $5 \mathrm{c})^{16}$. For interest associations, the effects of interethnic contact are in the same direction, though, they do not reach the boundary of significance. ${ }^{17}$.

Our findings regarding the relationship between migrant stock and perceptions of ethnic threat are somewhat mixed. At the neighbourhood level, a larger percentage of minorities from non-Western descent are positively related to perceptions of ethnic threat, whereas living in municipalities with higher percentages of non-Western minorities is negatively related to natives' level of perceived ethnic threat (Table 3, Model 3$)^{18}$. Interestingly, perceptions of ethnic threat are unrelated to involvement in leisure or interest associations at all.

\section{Conclusions and Discussion}

With rising levels of ethnic diversity in many Western countries, both scholars and politicians became increasingly interested in the consequences for social cohesion in general and social capital in particular $[4,5]$. The aim of our study was twofold. First, we examined whether living in ethnically more diverse Dutch neighbourhoods and municipalities influences people's likelihood to be involved in bonding and bridging associations. We differentiated between leisure (e.g., sport and cultural associations) and interest associations (e.g., neighbourhood or tenants associations), which are locally oriented, serving needs of locals and reflect relatively high levels of face-to-face contacts [19]. We expected that particularly involvement in these types of associations might be influenced by the level of ethnic diversity of people's 


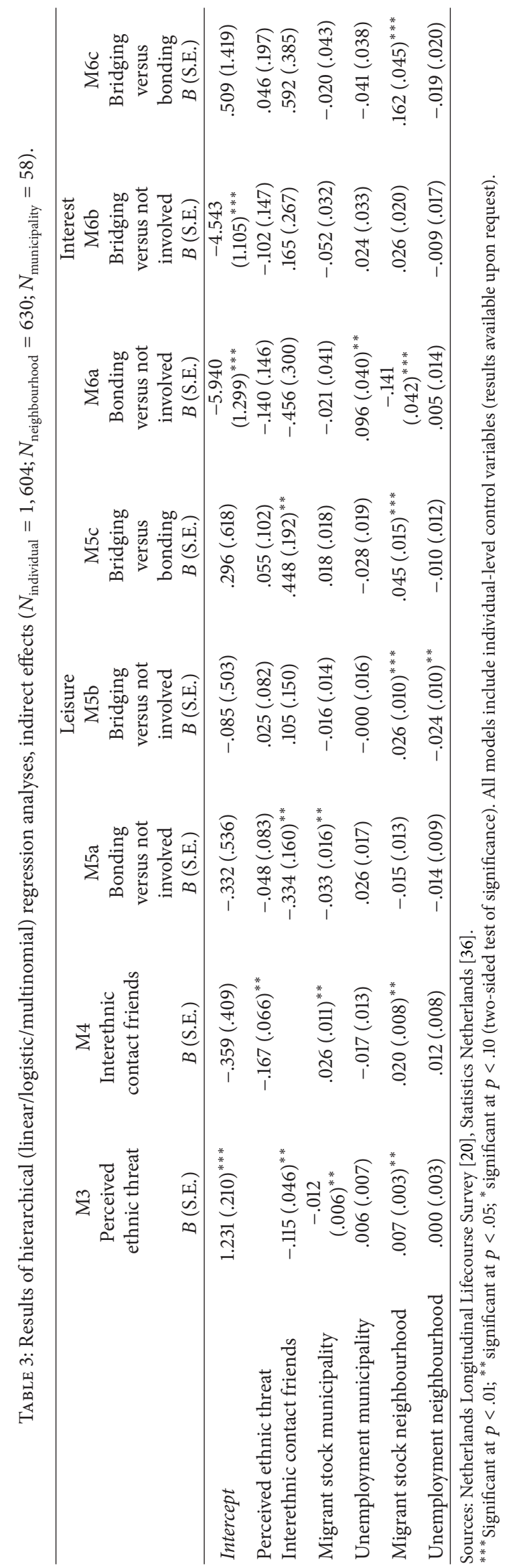


TABLE 4: Descriptive statistics for individual- and contextual-level variables $\left(N_{\text {individual }}=1,604 ; N_{\text {neighbourhood }}=630 ; N_{\text {municipality }}=58\right)$.

\begin{tabular}{|c|c|c|c|}
\hline Variable & Range & Mean/percentage & S.D. \\
\hline \multicolumn{4}{|l|}{ Individual level } \\
\hline \multicolumn{4}{|l|}{ Dependent variables, formal social capital } \\
\hline \multicolumn{4}{|l|}{ Involvement in leisure associations } \\
\hline Not involved leisure association & $0 / 1$ & $64.21 \%$ & \\
\hline Involved bonding leisure association & $0 / 1$ & $18.89 \%$ & \\
\hline Involved bridging leisure association & $0 / 1$ & $16.90 \%$ & \\
\hline \multicolumn{4}{|l|}{ Involvement in interest associations } \\
\hline Not involved interest association & $0 / 1$ & $89.90 \%$ & \\
\hline Involved bonding interest association & $0 / 1$ & $5.42 \%$ & \\
\hline Involved bridging interest association & $0 / 1$ & $4.68 \%$ & \\
\hline \multicolumn{4}{|l|}{ Mediating variables } \\
\hline Perceived ethnic threat & $0-4$ & 1.58 & .92 \\
\hline Interethnic contact & $0 / 1$ & $32.04 \%$ & \\
\hline \multicolumn{4}{|l|}{ Control variables individual level } \\
\hline \multicolumn{4}{|l|}{ Educational attainment } \\
\hline Primary/lower secondary education (incl. missing) & $0 / 1$ & $16.96 \%$ & \\
\hline Higher secondary/intermediate vocational educ. & $0 / 1$ & $45.89 \%$ & \\
\hline Vocational college & $0 / 1$ & $24.75 \%$ & \\
\hline University (ref.) & $0 / 1$ & $12.41 \%$ & \\
\hline \multicolumn{4}{|l|}{ Employment situation } \\
\hline Working (ref.) & $0 / 1$ & $76.18 \%$ & \\
\hline Studying & $0 / 1$ & $11.72 \%$ & \\
\hline Neither working nor studying & $0 / 1$ & $12.09 \%$ & \\
\hline \multicolumn{4}{|l|}{ Income per month } \\
\hline Less than 1,500 euro & $0 / 1$ & $19.83 \%$ & \\
\hline Between 1,500 and 2,499 euro & $0 / 1$ & $19.95 \%$ & \\
\hline Between 2,499 and 3,499 euro & $0 / 1$ & $22.88 \%$ & \\
\hline More than 3,500 euro (ref.) & $0 / 1$ & $24.13 \%$ & \\
\hline Income missing & $0 / 1$ & $13.22 \%$ & \\
\hline \multicolumn{4}{|l|}{ Religiosity } \\
\hline Church attendance - never (ref.) & $0 / 1$ & $57.04 \%$ & \\
\hline Church attendance-less than once a month & $0 / 1$ & $30.74 \%$ & \\
\hline Church attendance-once a month or more & $0 / 1$ & $12.22 \%$ & \\
\hline Partner (no partner = ref.) & $0 / 1$ & $80.86 \%$ & \\
\hline Children (no children = ref.) & $0 / 1$ & $60.47 \%$ & \\
\hline Female (male $=$ ref.) & $0 / 1$ & $53.87 \%$ & \\
\hline Age $(19.43=0)$ & $0-30.67$ & 17.07 & 9.08 \\
\hline \multicolumn{4}{|l|}{ Neighbourhood-level variables $(N=630)$} \\
\hline Percentage of non-Western immigrants & $0-76$ & 11.03 & 12.23 \\
\hline Ethnic fractionalization & $.00-.65$ & .31 & .15 \\
\hline Number of unemployment benefit recipients per 1,000 inhabitants aged 15-64 & $0-700$ & 63.65 & 73.94 \\
\hline \multicolumn{4}{|l|}{ Municipality-level variables $(N=58)$} \\
\hline Percentage of non-Western immigrants & $1-37$ & 9.07 & 8.47 \\
\hline Ethnic fractionalization & $.06-.61$ & .29 & .14 \\
\hline Number of unemployment benefit recipients per 1,000 inhabitants aged 15-64 & $10-38$ & 26.16 & 6.49 \\
\hline
\end{tabular}

Sources: The Netherlands Longitudinal Lifecourse Study [20], Statistics Netherlands [36]. 
direct living environment. In line with earlier studies on the relationship between ethnic diversity and social capital in the Netherlands $[8,9,22]$, we focused on the neighbourhood and municipality level, which we consider as relevant contexts with regard to involvement in locally oriented associations.

Second, our aim was to gain more insight into underlying explanations for a relationship between ethnic diversity and associational involvement. So far, research has largely neglected to take into account the ethnic composition of voluntary associations and to consider indirect relationships between ethnic diversity and involvement in bonding and bridging associations. If ethnic diversity has opposite effects on involvement in bonding and bridging associations or indirect effects are contradictory, such effects might cancel each other out. This might explain why evidence for a detrimental influence of ethnic diversity is particularly weak for associational involvement [5].

Evidence for a general negative impact of the level of ethnic diversity of people's living environment on their involvement in bonding and bridging voluntary associations is limited and varies across different types of associations. Only for leisure associations, living in municipalities with a larger percentage of non-Western minorities substantially decreases the likelihood to be involved in bonding associations. Based on Putnam's constrict theory, we would expect a similar detrimental influence of migrant stock on involvement in bridging associations, which we did not find. Those respondents, who are involved in leisure associations and live in ethnically more heterogeneous neighbourhoods, are more likely to be involved in bridging as compared to bonding leisure associations. For involvement in interest associations only at the neighbourhood level we found similar, though less substantial, relationships with ethnic diversity. As such, our results do not lend support to the expectations derived from constrict theory.

Our aim was also to shed more light on underlying explanations for a relationship between ethnic diversity and associational involvement. Based on conflict (e.g., $[11,12,25])$ and contact (e.g., $[13,15])$ theories we empirically tested the role of perceived ethnic threat and interethnic contact, respectively. As we expected, based on conflict theory, living in neighbourhoods with more minorities from non-Western descent is positively related to people's level of perceived ethnic threat. However, at the municipality level we found an opposite effect, as higher proportions of non-Western ethnic minorities are negatively related to perceptions of ethnic threat. Earlier research pointed at the so-called "familiarization effect" $[42,45]$, boiling down to the idea that people living in ethnically more diverse environments get used to the presence of ethnic minorities and, consequently, perceive less ethnic threat. Living in close proximity to ethnic minorities in one's own neighbourhood might be more threatening than living in an ethnically heterogeneous municipality.

Contradictory to what we expected and at odds with earlier European findings [16], perceptions of ethnic threat are unrelated to associational involvement, which refutes our hypotheses derived from conflict theory [11, 12, 25]. Apparently, perceptions of ethnic threat do not translate into higher levels of out-group derogation and in-group solidarity reflected in less involvement in bridging associations and more involvement in bonding associations, respectively.

As we expected, living in municipalities or neighbourhoods with a larger percentage of non-Western minorities increases the likelihood to have interethnic contact with friends. This corresponds with earlier findings in Europe as well as the USA (e.g., $[28,29,46,47])$ and holds for both contextual levels. Our results indicate, moreover, that those people, who are involved in leisure associations and have interethnic contact, are more likely to be involved in bridging rather than bonding associations. This means that interethnic contact not only influences attitudes, reducing prejudice and anxiety $[13,33]$, but also is related to behavioural outcomes in terms of being more likely to be involved in bridging as compared to bonding voluntary associations.

However, contradictory to our expectations derived from contact theory $[13,15]$ and to earlier European findings [16], having interethnic contact hardly affects (bonding and bridging) associational involvement directly. As interethnic contact reduces intergroup anxiety $[32,33]$ and might take away a psychological threshold to become involved in ethnically mixed associations, we expected that interethnic contact would be positively related to involvement in bridging associations. Although for both leisure and interest organizations the effects of interethnic contact point in the expected direction, they do not reach significance. As such, our findings do not lend support for contact theory. Only for leisure associations, having interethnic contact with friends is negatively related to the likelihood to be involved in bonding associations. This might reflect a deprovincialization effect (i.e., a reassessment of one's ethnic in-group) as proposed by Pettigrew [14], though this could also be explained by the influence of recruitment [31]. Although contacts with outgroup and in-group members are not completely mutually exclusive, due to time constraints, having more intergroup contact might reduce intragroup contact. Consequently, the likelihood to become informed about or even recruited into bonding associations might decrease.

Our findings show that the impact of ethnic diversity differs for involvement in bonding and bridging associations. Not taking into account the ethnic composition of voluntary associations, these nuances would not be visible, leading to different conclusions. Moreover, our results indicate that ethnic diversity is only indirectly related to associational involvement via interethnic contact and only for leisure associations. As such, our study provides no evidence that the lack of support for a direct relationship between ethnic diversity and associational involvement in many earlier studies is due to contradictory indirect effects cancelling each other out. In addition, we find support for an influence of ethnic diversity on associational involvement, interethnic contact, and perceived ethnic threat at the municipality as well as neighbourhood levels, illustrating that both environments are relevant and influence people's attitudes and behaviour. 
Finally, we would like to draw attention to several limitations to this study and directions for future research. First, as we found negative influences of migrant stock only on involvement in bonding (leisure and interest) organizations, our findings might (partly) point at a supply side effect. If municipalities (or neighbourhoods) become ethnically more diverse, this might become reflected in the ethnic composition of the voluntary associations available. As a consequence, it might be more difficult or even impossible to find an association with only in-group members, while there are more possibilities to become involved in bridging associations. This corresponds with earlier findings on the impact of ethnic diversity on informal social capital $[8,9]$, showing that informal contacts with in-group members decrease, while contacts with out-group members increase with higher levels of ethnic diversity.

In this study, we were unable to directly consider the availability of bonding and bridging associations in people's neighbourhood and municipality. Future research should incorporate the supply-side in this respect more profoundly. However, as no data are available covering the availability of different types of voluntary associations including their ethnic composition in the Netherlands, focusing on smaller geographical areas could be a fruitful direction to proceed.

Second, our results are based on cross-sectional data, which do not allow us to draw conclusions with regard to the causal directions of the relationships found. In particular the causal order between interethnic contact and involvement in bridging associations is not uncontested, as involvement in ethnically mixed voluntary associations could also lead to interethnic contact. In that case, one would expect, however, a strong positive relationship between interethnic contact and the odds of involvement in bridging associations versus not being involved, which we do not find. Using an alternative measure of interethnic contact at work/school yields substantially comparable results. As this type of contact is less voluntary in nature, a reversed causal order is largely ruled out.

Third, earlier European research revealed that perceptions of ethnic threat are negatively related to associational involvement, however, without considering the ethnic composition of these associations [16]. It remains to be further explored why this was not found for the Netherlands. It might be the case that perceptions of ethnic threat more strongly induce withdrawal from voluntary associations for older age cohorts. As our conclusions only pertain to people younger than 50 years old, this might explain the absence of a negative relationship between perceptions of ethnic threat and associational involvement.

Summarizing, we found only limited support for a general negative influence of living in ethnically more diverse environments on people's associational involvement: ethnic diversity is only (substantially) negatively related to involvement in bonding leisure associations. This might point at a supply-side effect, rather than at a general pattern of "hunkering down" $([3], 149)$. Our findings empirically underline the importance of distinguishing bonding and bridging voluntary associations and including underlying explanations (i.e., perceived ethnic threat and interethnic contact), to shed more light on the relationship between the ethnic composition of people's living environment and associational involvement.

\section{Appendix}

See Table 4.

\section{Conflict of Interests}

The authors declare that there is no conflict of interests regarding the publication of this paper.

\section{Acknowledgments}

This study is part of a project supported by the Netherlands Organization for Scientific Research (Grant number 432-008005). The authors would like to thank the reviewers of Urban Studies Research for their constructive comments and Joran Laméris for her help with the robustness analyses including measures of ethnic segregation.

\section{Endnotes}

1. Research focusing on attitudinal indicators of social cohesion mainly focused on measures related (only) to the out-group, for example, out-group trust [48] or interethnic tolerance [22]; however, see also Schmid et al. [49], who differentiate between out-group trust and in-group trust.

2. The causal order is not unambiguous here. We will come back to this in our discussion section.

3. Using panel data, one has to be aware of the likelihood of panel attrition. Overall, men, younger people, and people living in the Western region and in more urbanized areas in wave 1 were less likely to participate in wave 2 [21]. We are, however, particularly interested in relationships between ethnic diversity, associational involvement, and our mediating mechanisms, and we will control for people's age and gender, while including specific indicators of people's municipality and neighbourhood in our models.

4. The item referring to involvement in sport associations was asked differently compared to the items regarding all other types of associations. First, respondents were asked which sport(s) they practice in general and which sport they practice most frequently. Only for this type of sport, respondents were subsequently asked whether they practice this sport in an association or not. These associations included formal sports associations but also fitness centers or sport accommodations for students or at work. Solely respondents, who are involved in an association, were asked about the ethnicity of other members. We will restrict our analyses to respondents involved in formal sports associations. 
5. For leisure associations, respondents were separately asked about their involvement in two different subtypes of associations. We considered respondents to be involved in bridging leisure associations, if they were involved in at least one bridging association. Respondents were considered as involved in bonding leisure associations if they were involved in at least one bonding association while not simultaneously in a bridging association.

6. For robustness analyses, we also consider interethnic contact at work or school. Respondents were asked how often they have contact at work or school with minorities from (i) Turkish, (ii) Moroccan, (iii) Surinamese/Antillean, or (iv) other non-Western descents. Answer categories ranged from "never" to "(almost) daily" on a seven-point scale. Our alternative interethnic contact measure reflects the mean score on the four items, with higher values referring to more (frequent) interethnic contact.

7. Additional robustness analyses, only using the first three items referring to perceptions of collective ethnic threat, yield substantially similar conclusions, with one minor exception (results available upon request). We will come back to this in Results. Given the rather high reliability of our scale and the fact that factor analysis points at one dimension, we decided to use all items in our perceived ethnic threat scale.

8. The original twelve categories referring to the Dutch educational tracks were condensed as follows: (1) at most primary education or lower secondary education (LBO/MAVO/VMBO), (2) higher secondary education (HAVO/VWO) or intermediate vocational (MBO), (3) vocational college (HBO), and (4) university (WO, bachelor, master, and Ph.D.). To keep our model as parsimonious as possible, we decided to include respondents without valid information regarding their level of educational attainment $(1.3 \%)$ in the first category.

9. The same holds for both mediating variables (not shown), that is, interethnic contact ( $\operatorname{Var}_{\text {municipality }}=.155$; Var $_{\text {neighbourhood }}=.000$ ) and perceived ethnic threat $\left(\operatorname{Var}_{\text {municipality }}=.054 ; \operatorname{Var}_{\text {neighbourhood }}=.041\right)$.

10. Our ethnic segregation measure is based on a multigroup dissimilarity index, which can be interpreted as the percentage of people who would have to move to a different living area to equalize the proportions of the different ethnic groups across all living areas, divided by the percentage of people who would have to move if the whole area was totally segregated [50]. We differentiated between natives, minorities from non-Western descent, and Western minorities. Using a two-group dissimilarity index, differentiating between natives and non-Western minorities yields substantially similar conclusions. At the municipality level, ethnic segregation is measured using information about neighbourhoods within the municipality. At the neighbourhood level, information about the ethnic composition of grid cells (100 by 100 meter) is used (see [51]).
11. All effects of our robustness analyses are in the same direction as our main results (Tables 2 and 3); however, some effects do no longer reach the conventional boundary of significance, while other effects become significant. We will come back to this in Results.

12. Using our ethnic fractionalization measure of ethnic diversity, the negative relationship between neighbourhood ethnic diversity and involvement in bonding leisure associations also becomes significant. If we control for ethnic segregation, the positive relationship between migrant stock at the municipality level and bridging versus bonding associational involvement in leisure organizations becomes significant.

13. At the municipality level, the negative relationship between migrant stock and involvement in bridging interest organizations becomes significant if we control for ethnic segregation.

14. We estimated the probabilities to be in one of the three categories for both dependent variables separately. The models refer to respondents in modal categories of our categorical determinants (see Table 4), as well as respondents with an average age. We considered the influence of migrant stock at the municipality or neighbourhood level (dependent on the findings in Table 2), for municipalities and neighbourhoods with average levels of unemployment. As our findings revealed an influence of ethnic diversity on involvement in leisure associations at the neighbourhood and municipality level, we decided to estimate the impact at both levels separately. First, we estimated the influence of ethnic diversity at the municipality level, holding the level of ethnic diversity at the neighbourhood level constant (i.e., using the average level of migrant stock). Subsequently, we calculated the impact of ethnic diversity at the neighbourhood level, controlling for the average level of ethnic diversity at the municipality level. For interest associations, we only considered the neighbourhood level, as we only found an influence of ethnic diversity at this level (Table 2). In all models, we only included significant parameter estimates. Random intercepts are set to zero.

15. If we use our alternative measure of interethnic contact, this negative relationship is no longer significant. As interethnic contact at work or school is less voluntary in nature, it is less likely to be influenced by perceptions of ethnic threat. Vice versa, this type of interethnic contact is less likely to influence perceptions of ethnic threat, as it is more superficial as compared to more intimate interethnic friendship.

16. If we control for the level of ethnic segregation at the municipality and neighbourhood level, these relationships no longer reach significance. This might be due to the fact that our ethnic segregation measure might also be related to the likelihood to have interethnic contact.

17. Using our measure of interethnic contact at work or school, both effects become significant as well.

18. Note that both effects no longer reach the boundary of significance, once we use our ethnic fractionalization 
measure of ethnic diversity. If we use our measure of perceptions of collective ethnic threat, the positive effect of migrant stock at the neighbourhood no longer reaches significance.

\section{References}

[1] W. A. Cornelius and M. R. Rosenblum, "Immigration and politics," Annual Review of Political Science, vol. 8, pp. 99-119, 2005.

[2] M. Hooghe, A. Trappers, B. Meuleman, and T. Reeskens, "Migration to European countries: a structural explanation of patterns, 1980-2004," International Migration Review, vol. 42, no. 2, pp. 476-504, 2008.

[3] R. D. Putnam, "E pluribus unum: diversity and community in the twenty-first century the 2006 johan skytte prize lecture," Scandinavian Political Studies, vol. 30, no. 2, pp. 137-174, 2007.

[4] A. Portes and E. Vickstrom, "Diversity, social capital, and cohesion," Annual Review of Sociology, vol. 37, pp. 461-479, 2011.

[5] T. van der Meer and J. Tolsma, "Ethnic diversity and its effects on social cohesion," Annual Review of Sociology, vol. 40, no. 1, pp. 459-478, 2014.

[6] F. Pichler and C. Wallace, "Patterns of formal and informal social capital in Europe," European Sociological Review, vol. 23, no. 4, pp. 423-435, 2007.

[7] C. J. Dawkins, “Outlook: two views on Robert D. Putnam's 'E Pluribus Unum: diversity and community in the twenty-first century the 2006 Johan Skytte prize lecture': reflections on diversity and social capital: a critique of Robert D. Putnam's 'E Pluribus Unum: diversity and community in the twenty-first century the 2006 Johan Skytte prize lecture," Housing Policy Debate, vol. 19, no. 1, pp. 207-217, 2008.

[8] T. Huijts, G. Kraaykamp, and P. Scheepers, "Ethnic diversity and informal intra- and inter-ethnic contacts with neighbours in The Netherlands: a comparison of natives and ethnic minorities," Acta Sociologica, vol. 57, no. 1, pp. 41-57, 2014.

[9] T. Huijts, R. Sluiter, P. Scheepers, and G. Kraaykamp, "Ethnic diversity and personal contacts at work and at school in the Netherlands: a comparison of natives and ethnic minorities," Journal of International Migration and Integration, vol. 15, no. 2, pp. 277-298, 2014.

[10] L. A. Coser, The Function of Social Conflict, Free Press, Glencoe, Ill, USA, 1956.

[11] H. M. Blalock, Toward a Theory of Minority Group Relations, John Wiley \& Sons, New York, NY, USA, 1967.

[12] P. Scheepers, M. Gijsberts, and M. Coenders, "Ethnic exclusionism in European countries: public opposition to civil rights for legal migrants as a response to perceived ethnic threat," European Sociological Review, vol. 18, no. 1, pp. 17-34, 2002.

[13] G. W. Allport, The Nature of Prejudice, Beacon Press, Boston, Mass, USA, 1954.

[14] T. F. Pettigrew, "Intergroup contact theory," Annual Review of Psychology, vol. 49, pp. 65-85, 1998.

[15] T. F. Pettigrew and L. R. Tropp, When Groups Meet: The Dynamics of Intergroup Contact, Psychology Press, New York, NY, USA, 2011.

[16] M. Savelkoul, M. Gesthuizen, and P. Scheepers, "The impact of ethnic diversity on participation in european voluntary organizations: direct and indirect pathways," Nonprofit and Voluntary Sector Quarterly, vol. 43, no. 6, pp. 1070-1094, 2014.
[17] P. Dekker and A. van den Broek, "Involvement in voluntary associations in North America and Western Europe: trends and correlates 1981-2000," Journal of Civil Society, vol. 1, no. 1, pp. 45-59, 2005.

[18] M. Gesthuizen, T. van der Meer, and P. Scheepers, "Ethnic diversity and social capital in Europe: tests of putnam's thesis in European countries," Scandinavian Political Studies, vol. 32, no. 2, pp. 121-142, 2009.

[19] T. W. van der Meer, M. te Grotenhuis, and P. L. Scheepers, "Three types of voluntary associations in comparative perspective: the importance of studying associational involvement through a typology of associations in 21 European Countries," Journal of Civil Society, vol. 5, no. 3, pp. 227-241, 2009.

[20] Netherlands Longitudinal Lifecourse Survey (NELLS), 2013.

[21] J. Tolsma, G. Kraaykamp, P. M. De Graaf, M. Kalmijn, and C. W. S. Monden, The Netherlands Longitudinal Lifecourse Study (NELLS, Panel), Radboud University Nijmegen, Tilburg University \& University of Amsterdam, Amsterdam, The Netherlands, 2014.

[22] J. Tolsma, T. van der Meer, and M. Gesthuizen, “The impact of neighbourhood and municipality characteristics on social cohesion in the Netherlands," Acta Politica, vol. 44, no. 3, pp. 286-313, 2009.

[23] D. Stolle, S. Soroka, and R. Johnston, "When does diversity erode trust? Neighborhood diversity, interpersonal trust and the mediating effect of social interactions," Political Studies, vol. 56, no. 1, pp. 57-75, 2008.

[24] M. McPherson, L. Smith-Lovin, and J. M. Cook, "Birds of a feather: homophily in social networks," Annual Review of Sociology, vol. 27, pp. 415-444, 2001.

[25] L. D. Bobo, "Prejudice as group position: microfoundations of a sociological approach to racism and race relations," Journal of Social Issues, vol. 55, no. 3, pp. 445-472, 1999.

[26] M. Coenders, M. Gijsberts, L. Hagendoorn, and P. Scheepers, "Introduction," in Nationalism and Exclusion of Migrants: CrossNational Comparisons, M. Gijsberts, L. Hagendoorn, and P. Scheepers, Eds., pp. 1-25, Ashgate, Aldershot, UK, 2004.

[27] T. F. Pettigrew, U. Wagner, and O. Christ, "Population ratios and prejudice: modelling both contact and threat effects," Journal of Ethnic and Migration Studies, vol. 36, no. 4, pp. 635-650, 2010.

[28] E. Schlueter and P. Scheepers, "The relationship between outgroup size and anti-outgroup attitudes: a theoretical synthesis and empirical test of group threat- and intergroup contact theory," Social Science Research, vol. 39, no. 2, pp. 285-295, 2010.

[29] U. Wagner, O. Christ, T. F. Pettigrew, J. Stellmacher, and C. Wolf, "Prejudice and minority proportion: contact instead of threat effects," Social Psychology Quarterly, vol. 69, no. 4, pp. 380-390, 2006.

[30] E. Schlueter and U. Wagner, "Regional differences matter: examining the dual influence of the regional size of the immigrant population on derogation of immigrants in Europe," International Journal of Comparative Sociology, vol. 49, no. 2-3, pp. 153-173, 2008.

[31] J. Wilson, "Volunteering," Annual Review of Sociology, vol. 26, pp. 215-240, 2000.

[32] R. Brown and M. Hewstone, "An integrative theory of intergroup contact," Advances in Experimental Social Psychology, vol. 37, pp. 255-343, 2005.

[33] T. F. Pettigrew and L. R. Tropp, "How does intergroup contact reduce prejudice? Meta-analytic tests of three mediators," European Journal of Social Psychology, vol. 38, no. 6, pp. 922-934, 2008. 
[34] S. Soroka, J. Helliwell, and R. Johnston, "Measuring and modelling trust," in Diversity, Social Capital and the Welfare State, F. Kay and R. Johnston, Eds., pp. 279-303, University of British Columbia Press, Vancouver, Canada, 2007.

[35] M. Hooghe, T. Reeskens, D. Stolle, and A. Trappers, "Ethnic diversity and generalized trust in Europe: a cross-national multilevel study," Comparative Political Studies, vol. 42, no. 2, pp. 198-223, 2009.

[36] Statistics Netherlands, Kerncijfers Wijken en Buurten 2012, 2014, http://www.cbs.nl.

[37] A. Alesina, A. Devleeschauwer, W. Easterly, S. Kurlat, and R. Wacziarg, "Fractionalization," Journal of Economic Growth, vol. 8, no. 2, pp. 155-194, 2003.

[38] L. Hagendoorn, "Ethnic diversity and the erosion of social capital?" Newsletter American Political Science Association, vol. 20, no. 1, pp. 12-14, 2009.

[39] N. Letki, "Does diversity erode social cohesion? Social capital and race in british neighbourhoods," Political Studies, vol. 56, no. 1, pp. 99-126, 2008.

[40] J. E. Curtis, E. G. Grabb, and D. E. Baer, "Voluntary association membership in fifteen countries: a comparative analysis," American Sociological Review, vol. 57, no. 2, pp. 139-152, 1992.

[41] J. Wilson and M. Musick, "Who cares? Toward an integrated theory of volunteer work," The American Sociological Review, vol. 62 , no. 5, pp. 694-713, 1997.

[42] S. L. Schneider, "Anti-immigrant attitudes in Europe: outgroup size and perceived ethnic threat," European Sociological Review, vol. 24, no. 1, pp. 53-67, 2008.

[43] T. A. Snijders and R. J. Bosker, Multilevel Analysis: An Introduction to Basic and Advanced Multilevel Modeling, Sage, Los Angeles, Calif, USA, 2nd edition, 2012.

[44] E. M. Uslaner, "Trust, diversity, and segregation in the United States and the United Kingdom," Comparative Sociology, vol. 10, no. 2, pp. 221-247, 2011.

[45] M. Savelkoul, P. Scheepers, J. Tolsma, and L. Hagendoorn, "AntiMuslim attitudes in the Netherlands: tests of contradictory hypotheses derived from ethnic competition theory and intergroup contact theory," European Sociological Review, vol. 27, no. 6, pp. 741-758, 2011.

[46] L. Sigelman, T. Bledsoe, S. Welch, and M. W. Combs, "Making contact? Black-white social interaction in an urban setting," American Journal of Sociology, vol. 101, no. 5, pp. 1306-1332, 1996.

[47] B. Martinović, "The inter-ethnic contacts of immigrants and natives in the Netherlands: a two-sided perspective," Journal of Ethnic and Migration Studies, vol. 39, no. 1, pp. 69-85, 2013.

[48] B. Lancee and J. Dronkers, "Ethnic, religious and economic diversity in dutch neighbourhoods: explaining quality of contact with neighbours, trust in the neighbourhood and interethnic trust," Journal of Ethnic and Migration Studies, vol. 37, no. 4, pp. 597-618, 2011.

[49] K. Schmid, A. A. Ramiah, and M. Hewstone, "Neighborhood ethnic diversity and trust: the role of intergroup contact and perceived threat," Psychological Science, vol. 25, no. 3, pp. 665674, 2014.

[50] S. F. Reardon and G. Firebaugh, "Measures of multigroup segregation," Sociological Methodology, vol. 32, pp. 33-67, 2002.

[51] Statistics Netherlands, Statistische Gegevens per Vierkant. Update 2014-10, Centraal Bureau voor de Statistiek, The Hague, The Netherlands, 2014. 

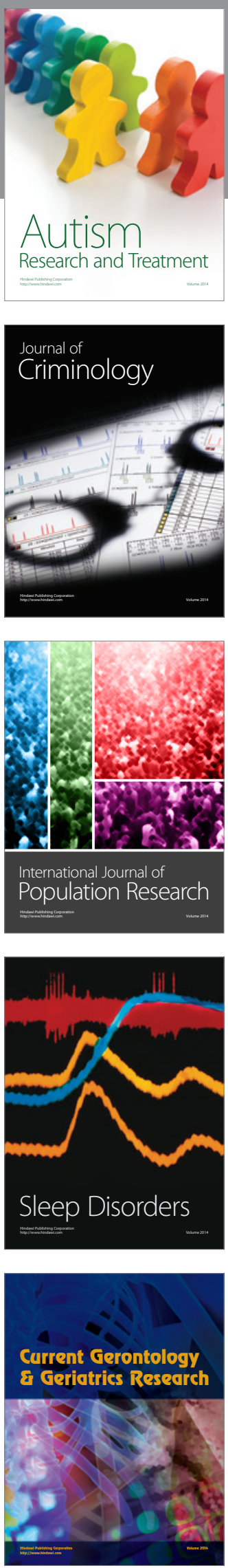
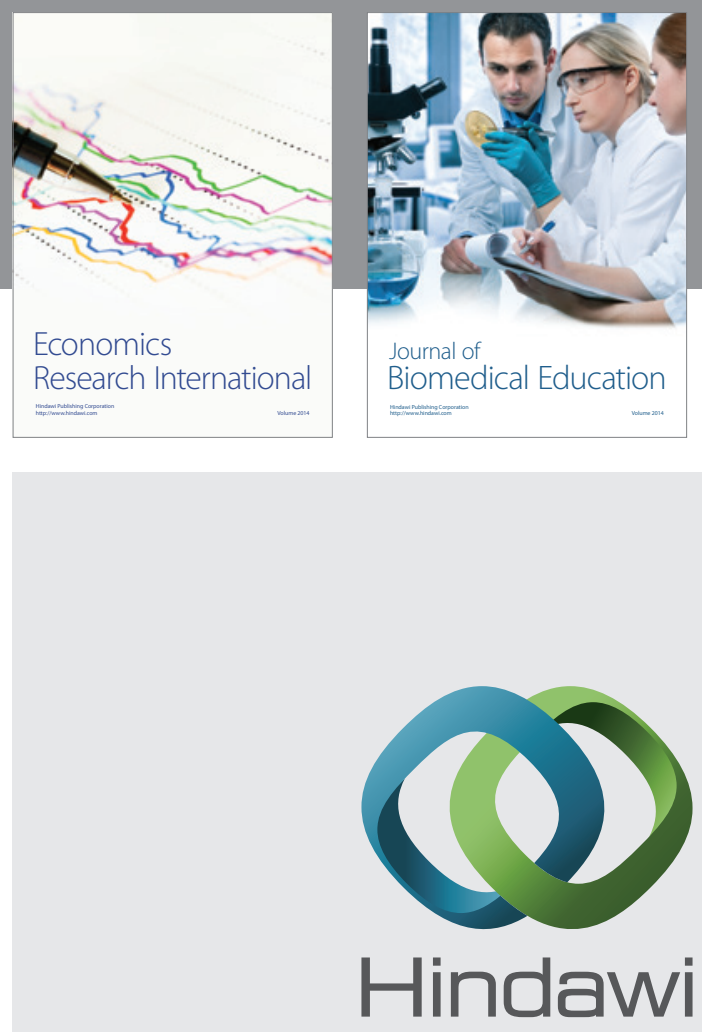

Submit your manuscripts at

http://www.hindawi.com
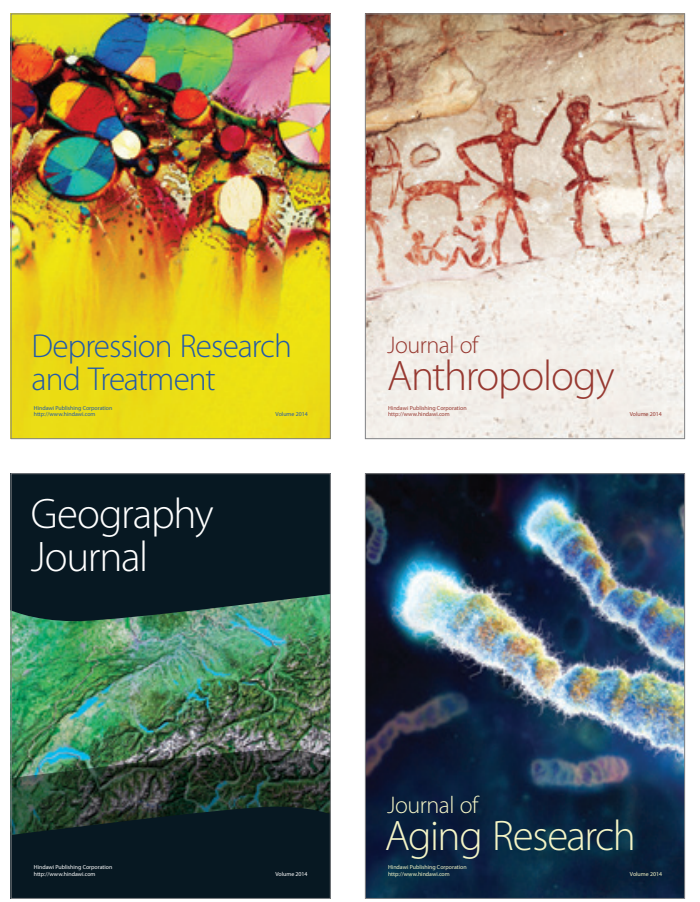
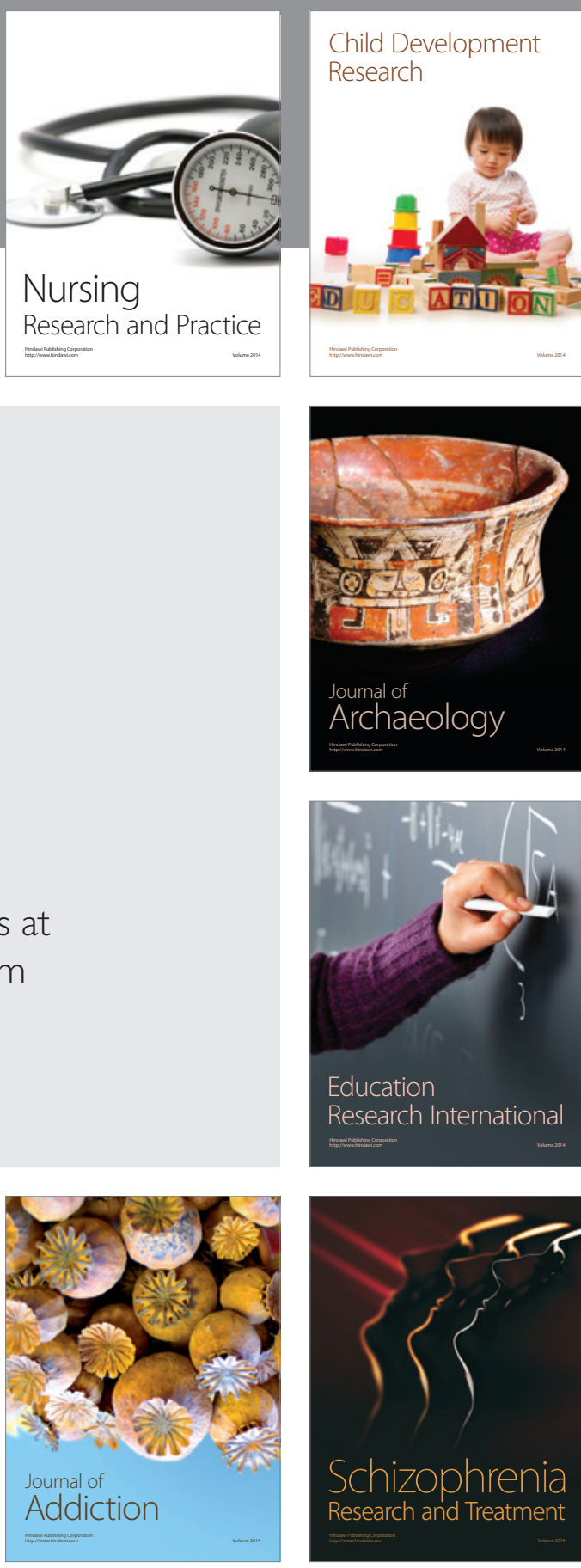

(D)
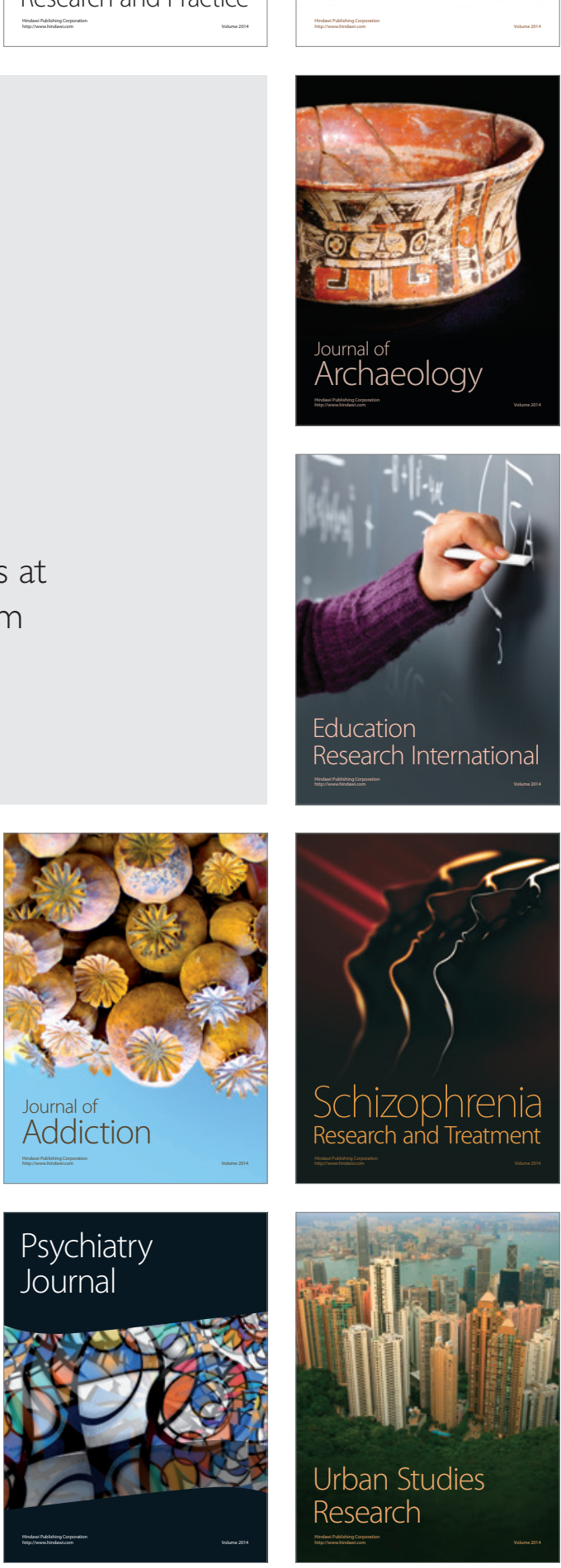